\title{
Extradimensional transfer in the discriminative learning of goldfish
}

\author{
W. A. TENNANT and M. E. BITTERMAN \\ University of Hawaii, Honolulu, Hawaii, 96822
}

\begin{abstract}
In Experiment I, one group of goldfish (TD) was trained to discriminate blue and green while a second group (PD) was exposed to the same colors in a "pseudodiscrimination," after which both groups were reinforced for response to a tone. The TD group subsequently showed a sharper auditory discrimination gradient than the PD group and performed better in a differentially reinforced tone discrimination. The former PD animals then were given true discrimination training and the former TD animals pseudodiscrimination training with the colors, after which the first group showed better tone discrimination than the second. These results are analogous to those found in pigeons and rats. In Experiment II, goldfish which were trained in an easy color discrimination and shifted to a more difficult tone discrimination performed better than a control group trained from the outset with the tones. This result suggests that the dimensional specificity of the processes responsible for "transfer along a continuum" cannot safely be assumed in the absence of appropriate controls.
\end{abstract}

Recent experiments both with rats and with pigeons show that ("true") discrimination training in one afferent dimension may sharpen gradients of generalization and otherwise improve discrimination in a different-even heteromodal-dimension, while training in a "pseudodiscrimination" (that is, with nondifferential reinforcement) may have opposite consequences (Bresnahan, 1970; Frieman \& Goyette, 1973; Honig, 1969; Thomas, 1969; Thomas, Freeman, Svinicki, Burr, \& Lyons, 1970; Thomas, Miller, \& Svinicki, 1971). The present work with goldfish provides some further indication of the phyletic generality of these findings, which have important implications for contemporary attention theory (Sutherland \& Mackintosh, 1971).

\section{EXPERIMENT I}

\section{Method}

In the first part of this experiment, the effects of true discrimination (TD) and pseudodiscrimination (PD) of color on an auditory discrimination were compared in a two-group design. In the second part of the experiment, the results of the first part were replicated with the roles of the two groups reversed.

Subjects. The subjects were 10 goldfish, each about $10 \mathrm{~cm}$ in length, and all experimentally naive. They were maintained on a 24-h feeding schedule in a temperature-controlled laboratory room.

Apparatus. Each subject was trained in its individual living tank which was carried to an experimental chamber located in a larger sound-attenuating enclosure. The training apparatus, mounted on a chassis of black Plexiglas, covered the top and front end of the tank. The manipulandum was a circular target, $4 \mathrm{~cm}$ in diam, presented at the front end of the tank. The target was fixed to a rod, the other end of which was inserted into the needle holder of a phonograph cartridge, and any contact of the animal with the target produced a voltage across the cartridge which was used to operate a response relay; the circuit has been described elsewhere (Woodard \& Bltterman, 1974). At the center

This work was supported by Grant MH-23294 from the Public Hodth Service. Reprints may bo obtained trom M. E. Bitterman, Laboratory of Sensory Sclences. 1993 East.Went Rosd, Honolulu, Hawall 96822 . of the target was a Plexiglas nipple through which liquid reinforcement (Biorell blended with tragacanth and water) could be delivered from a syringe by a Peti-Pump (Harvard Apparatus Co.). The target could be illuminated diffusely by $7.5-\mathrm{W}$ Christmas-tree lamps in a light box behind it, while auditory stimuli could be presented through a speaker mounted on one wall of the enclosure. The lamp colors used were white, red, green, and blue. The auditory stimuli were tones, nominally 200 , 400,600 , and $800 \mathrm{~Hz}$; calibration with a hydrophone showed them to be $217 \mathrm{~Hz}$ at $35 \mathrm{~dB}, 395$ at $33 \mathrm{~dB}, 560$ at $17 \mathrm{~dB}$, and 785 at $10 \mathrm{~dB}\left(\mathrm{re} .1 \mu \mathrm{N} / \mathrm{m}^{2}\right.$ ). All events of the experiment were controlled by programming equipment cabled to the chamber, and responses were recorded with a printing counter.

Procedure. The animals learned readily to strike at the target and then were given 10 sessions of variable interval (VI) 1-min training with a white target light which served as the stimulus. The reinforcement was a drop of liquid food delivered through the nipple. Each session began with a warm-up period during which the white target was presented and response to it was reinforced on a VI 1 -min schedule until the animal had made at least 60 responses in $3 \mathrm{~min}$. Then there were 103 -min presentations of the white stimulus, each preceded by a time-out in darkness of at least $15 \mathrm{sec}$, with any response in the time-out penalized by resetting of a 5 -sec penalty timer which postponed the next presentation. The measure of performance was the number of responses made during each 3-min presentation exclusive of responses in a 5 -sec period following each reinforcement, the purpose of this exclusion being to ensure that the measure of performance would not be contaminated by residual consummatory responses. After discriminative training was begun, exactly the same procedure was employed during presentations of the positive and negative stimuli except that during presentations of a negative stimulus, no food was actually delivered.

The design of the experiment is illustrated in Table 1, which details the training of two sample subjects. In Stage 1, one group of five of the animals had TD training with green and blue stimuli, green positive for some and blue positive for others. A second group of five animals (comparable to the first with respect to adjustment in pretraining) had PD training with the same stimuli-each color equally often reinforced and nonreinforced. There were 10 daily training sessions with six presentations of each color (in balanced quasirandom orders) in each session. In Stage 2, there were five sessions in each of which, for both groups, there were 12 reinforced presentations 
Table 1

Design of Experiment I Illustrated in Terms of the Treatment of Two Sample Subjects*

\begin{tabular}{|c|c|c|}
\hline Stage & Sessions & Subject 1 \\
\hline 1 & 10 & $\mathrm{G}+. \mathrm{G}-. \mathrm{B}+. \mathrm{B}-$ \\
\hline 2 & 5 & $\mathrm{R} / 200+$ \\
\hline 3 & 2 & $\mathrm{R} / 200-, \mathrm{R} / 400-, \mathrm{R} / 600-, \mathrm{R} / 800_{-}$ \\
\hline 4 & 1 & $\mathrm{R}_{i} 600+. \mathrm{R}_{2}^{\prime} 200-$ \\
\hline 5 & 3 & $B+G$ \\
\hline 6 & 5 & $\begin{array}{c}\mathrm{G}^{+}, \mathrm{G}-. \mathrm{B}+. \mathrm{B}-. \mathrm{R} / 200+, \mathrm{R} 200- \\
\mathrm{R} / 400+, \mathrm{R} / 400-\end{array}$ \\
\hline 7 & 12 & $\mathrm{G}+. \mathrm{G}-. \mathrm{B}+. \mathrm{B}-\quad \mathrm{G}+. \mathrm{B}-$ \\
\hline 8 & 12 & $\mathrm{R} / 200+. \mathrm{R} / 400$ \\
\hline
\end{tabular}

*4bbreviations: $G$, green; B. blue: $R$. red: 200.400 .600 , and 800. auditory frequencies $(H z) ;+$. reinforced: - . unreinforced. Subject 1 begins as a TD animal and then becomes a PD animat, while the reverse is the of Subject?.

of red light combined with the $200-\mathrm{Hz}$ tone for half the animals (distributed over the two groups) or with the $800-\mathrm{Hz}$ tone for the remaining animals. In Stage 3, auditory generalization was measured in both groups. There were two sessions in each of which (in balanced quasirandom orders) there were four unreinforced presentations of red 200 , red 400 , red 600 , and red 800 . In Stage 4 (a single 12-trial session), there was a reversal test of auditory discrimination. The reinforced tone of Stage 2 now was negative, and the positive tone (never previously reinforced) was $400 \mathrm{~Hz}$ removed from the negative: both tones, presented in balanced orders, were accompanied by the red light.

In Stage 5, there were three sessions of 12 trials each in which both groups were trained to discriminate green and blue. For the former TD group, the previously reinforced color now was negative; for the former PD group, green was positive in some cases and blue in others. Then, in Stage 6, both groups had five PD sessions of 16 trials each in which green, blue, and either red 200 and red 400 (for animals trained in Stage 2 with red 200) or red 600 and red 800 (for animals trained in Stage 2 with red 800 ). In Stage 7 , there were 12 sessions of 12 trials each in which the former TD group had further PD training with green and blue, while the former PD group had TD training with green and blue, the reinforced color of Stage 5 now unreinforced. In Stage 8, there were 12 sessions of 12 trials each in which the animals of both groups were trained to discriminate either red 200 (positive) and red 400 (negative) or red 800 (positive) and red 600 (negative).

\section{Results}

In Stage 1, the TD group rapidly mastered the color discrimination, while the PD group showed no substantial preference for either stimulus, its absolute level of response to both being intermediate between the levels of TD response to the positive and negative stimuli. In Stage 2, both groups responded at the same high level to the single positive auditory stimulus. In the unreinforced generalization test of Stage 3, however, the TD group discriminated sharply between the previously reinforced frequency and the new frequencies, while the PD group did not. Relative generalization gradients for the 1st day of testing are plotted in Figure 1, and the significance of the difference between the groups on that day is indicated by the interaction of groups with stimuli $[F(3 / 24)=5.35, p<.01]$. By the 2 nd day of testing, extinction was relatively far advanced for both groups, the generalization gradients were flat, and the difference between them insignificant. The TD group showed superior auditory discrimination also on the single day of differentially reinforced training in Stage 4, despite the fact that the positive stimulus of Stage 2 now was negative. Trial-by-trial plots of the performance of the two groups are presented in Figure 2, and the significance of the difference between them is reflected in the interaction of groups with stimuli $[F(1 / 8)=14.38, p<.01]$. We conclude then that auditory discrimination was better after TD as compared with PD training with color.

In Stage 5, both groups mastered the color discrimination, the TD animals more rapidly $[F(1 / 8=8.02, p<.01]$ despite the fact that the positive color for those animals had been negative when the stimuli were last encountered. In the PD training of Stage 6, all color and frequency preferences rapidly disappeared. In Stage 7, as the former TD animals now were given $\mathrm{PD}$ training, the former $\mathrm{PD}$ animals reacquired the color discrimination, but only very slowly. As shown in Figure 3, their performance is considerably worse than that of the former TD group on the same problem at the very outset of the experiment, which provides a useful no-training control

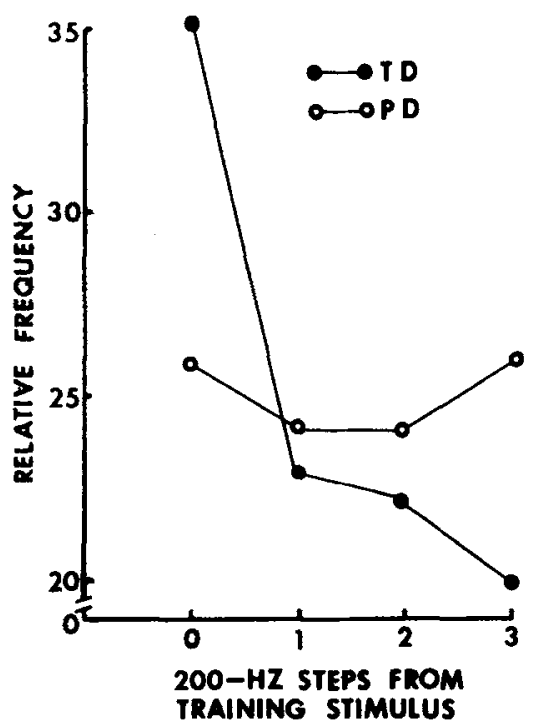

Figure 1. Relative auditory generalization gradients for the TD and PD groups in Stage 3 of Experiment $I$.

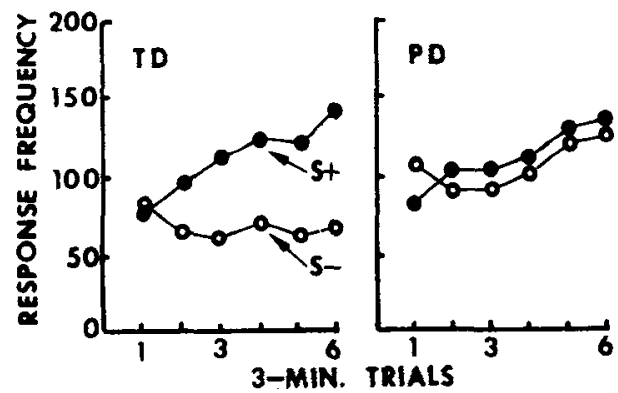

Figure 2. Auditory discrimination of the TD and PD groups in Stage 4 of Experiment I. 
$[F(1 / 8)=7.98, p>.01]$. As Figure 4 shows, however, the performance of the former PD (now TD) animals in the difficult auditory discrimination of Stage 8 was substantially better $[\mathrm{F}(1 / 8)=34.62, \mathrm{p}<.01]$ than that of the former TD animals which, after PD experience in Stages 6 and 7 , progressed only very slowly. We conclude that there is a positive extradimensional transfer effect of TD training in goldfish which can be reversed by $P D$ training, and a negative extradimensional transfer effect of PD training which can be reversed by TD training.

\section{EXPERIMENT II}

The mechanisms responsible for extradimensional transfer may play a role also in intradimensional transfer. Particularly interesting in this respect by reason of its implications for attention theory is the phenomenon of "transfer along a continuum": dogs (Pavlov, 1927), rats (Lawrence, 1952), pigeons (Mackintosh \& Little, 1970; Marsh, 1969), and certain fishes (Hemmings, 1965) that are trained first on an easy discrimination and then shifted to a difficult discrimination in the same dimension perform better than control animals trained throughout on the difficult discrimination. That the dimensional specificity of such results cannot be taken for granted is emphasized by the results of the experiment now to be reported in which the easy and difficult discriminations were in different dimensions.

\section{Method}

The subjects were nine naive goldfish drawn from the same population as those of the first experiment and maintained the same way. The apparatus and the general training procedure also were the same.

The experiment proper consisted of two stages. In Stage 1, five animals comprising the C-T group were trained for three

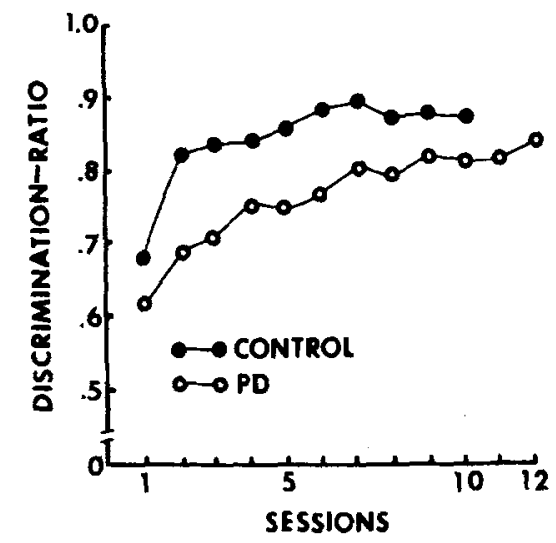

Figure 3. Color discrimination of the former PD group in Stage 7 and the original TD group (control) in Stage 1 of Experiment I.

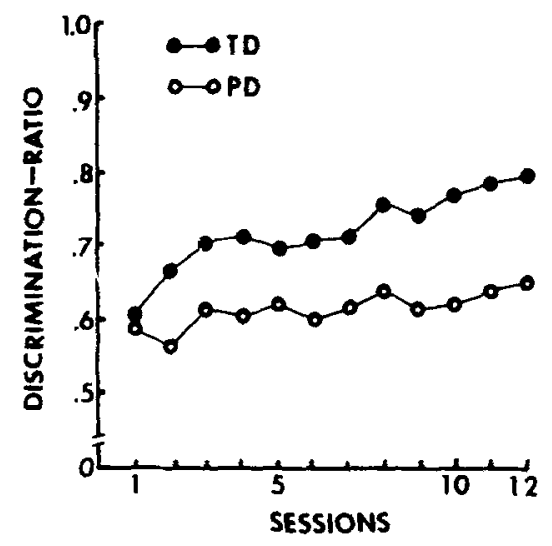

Figure 4. Auditory discrimination of the TD and PD groups in Stage 8 of Experiment 1.

sessions on a discrimination between green and blue (green positive for two, and blue positive for the others). Four animals in the T-T group were trained with a white target together with $400-\mathrm{Hz}$ and $800-\mathrm{Hz}$ tones (the lower frequency positive for two of the animals and the higher one positive for the others). There were 12 trials in each session, six with the positive stimulus and six with the negative in balanced orders. In Stage 2, both groups were trained with the tones for three sessions exactly as were the $T-T$ animals in the first stage. For the $T-T$ animals, the positive frequency of the first stage remained positive. Of the C-T animals, two were trained with the lower frequency positive and the rest with the higher frequency positive.

\section{Results}

The data for the two groups are plotted in Figure 5. As the curves indicate, the performance of the C-T group in Sessions 4-6 (its first three sessions of tone discrimination) was superior to that of the $T-T$ group both in Sessions $1-3[\mathrm{~F}(1 / 7)$ for the interaction of groups and stimuli $=8.35, p<.05]$ and in sessions 4.6 $[F(1 / 7)=7.41, p<.05]$. The first comparison simply shows that training in the easy color discrimination facilitated performance in the difficult tone discrimination. The second comparison shows that training in the color discrimination contributed more to performance in the tone discrimination than did training in the tone discrimination itself.

\section{DISCUSSION}

The present experiments show a substantial amount of extradimensional transfer, both positive and negative, in goldfish, just as is found in pigeons and rats, although the source of the transfer remains to be determined. It has been suggested by Thomas and colleagues (Thomas, 1969; Thomas et al., 1970) that "general attentiveness" is increased by differential reinforcement and decreased by nondifferential reinforcement, but that notion does not take us very far beyond the data and may perhaps have the disadvantage of discouraging search for more peripheral determinants (Hall \& Honig, 1974).

Thomas and colleagues have suggested also that the fact of extradimensional transfer is not easily reconciled 


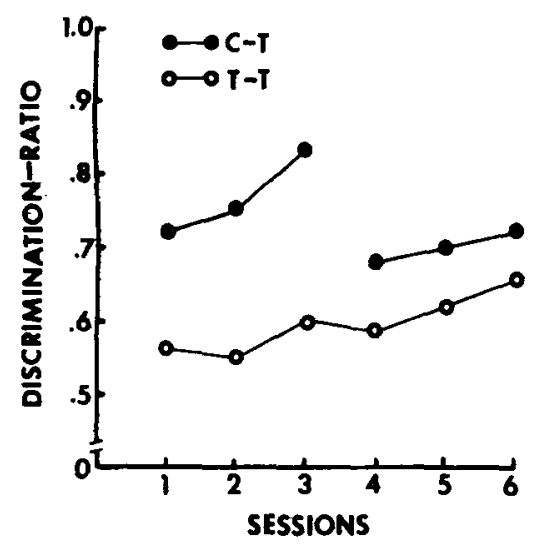

Figure 5. The performance of the color-tone (C-T) and tone-tone (T-T) groups in Experiment II.

with what they term the "inverse hypothesis" of conventional attention theory (see, for example, Sutherland \& Mackintosh, 1971), according to which differential reinforcement in one dimension tends to weaken (and nondifferential reinforcement to strengthen) attention in other dimensions, and they have been led in consequence to question whether the hypothesis really is required. Whatever the answer insofar as the results for pigeons and rats are concerned, the results for fishes clearly do not require it. Goldfish and carp fail to show greater intradimensional than extradimensional transfer (Tennant \& Bitterman, 1973, 1975). They do show overshadowing and blocking (Tennant \& Bitterman, 1975), but those phenomena can be understood without reference to attention, either general or specific (Wagner \& Rescorla, 1972). Although Hemmings (1965) invoked Sutherland's theory to account for the finding that discrimination between circle and square was facilitated in some fishes (guramis and blue acaras) by pretraining with the circle and rectangles of the same area, but not facilitated in other fishes (swordtails) by pretraining with the circle and squares of different area, the confounding of subjects and conditions (even apart from other difficulties) deprives his work of any significance. Our own results demonstrate that proper controls for general facilitation must be used in experiments on transfer along a continuum before dimensional specificity can be assumed. There is nothing in the present data for fishes to warrant the conclusion that discriminative training in one dimension either differentially improves performance in the same dimension or impairs performance in other dimensions.

\section{REFERENCES}

Bresnahan, E. L. Effects of extradimensional pseudodiscrimination and discrimination training upon stimulus control. Journal of Experimental Psychology, 1970, $85,155-156$.

Frieman, J., \& Goyette, C. H. Transfer of training across stimuius modality and response class. Journal of Experimental Psychology, 1973, 97, 235-241.

Hall, G.. \& Honig, W. K. Stimulus control after extradimensional training in pigeons: A comparison of response contingent and noncontingent training procedures. Journal of Comparative and Physiological Psychology, 1974, 87, 945-952.

Hemmings, $G$. The effect of pretraining in the circle/square discrimination. Animal Behaviour, 1965, 13, 212-216.

Honig, W. K. Attentional factors governing the slope of the generalization gradient. In R. M. Gilbert and N. S. Sutherland (Eds.), Animal discrimination learning. London: Academic Press, 1969

Lawrence, D. H. The transfer of a discrimination along a continuum. Journal of Comparative and Physiological Psychology, 1952, 45, 511-516.

Mackintosh, N. J., \& Little, L. An analysis of transfer along a continuum. Canadian Journal of Psychology, 1970, 24, 362-369.

Marsh, G. An evaluation of three explanations for the transfer of discrimination effect. Journal of Comparative and Phy siological Psychology, 1969, 68, 268-275.

Pavlov, I. P. Conditioned reflexes. Oxford: Humphrey Milford, 1927.

Sutherland, N. S., \& Mackintosh, N. J. Mechanisms of animal discrimination learning. Lond on: Academic Press, 1971.

Tennant, W. A., \& Bitterman, M. E. Some comparisons of intraand extradimensional transfer in discriminative learning of goldfish. Joumal of Comparative and physiological Psy chology, 1973,83, 134-139.

Tennant. W. A., \& Bitterman, M. E. Blocking and oversh adowing in two species of fish. Journal of Experimental Psychology: Animal Behavior Processes, 1975, 104, 22-29.

Thomas, $D_{t} R$. The use of operant conditioning techniques to investigate perceptual processes in animals. In $R$. M. Gilbert and N, S. Sutherland (Eds.), Animal discrimination learning. London: Academic Press, 1969.

Thomas, D. R., Freeman, F., Svinicki, J. G., Burr, D. E. S., \& Lyons, J. Effects of extradimensional training on stimulus generalization. Journal of Experimental Psychology Monographs, $1970,83,1-21$.

Thomas, D. R., Miller, J. T., \& Svinicki, J. G. Nonspecific transfer effects of discrimination training in the rat. Journal of Comparative and Physiological Psychology, 1971, 74, 96-101.

Wagner, A. R., \& Rescorla, R. A. Inhibition in Pavlovian conditioning: Application of a theory. In R. A. Boakes and $M$. S. Halliday, Inhibition and learning. London: Academic Press. 1972 .

Woodard, W. T., \& Bitterman, M. E. Improved techniques for the measurement of consummatory behavior in fishes. Behavior Research Methods \& Instrumentation, 1974, 6, 321-324.

(Received for publication December 13, 1974; accepted January 6,1975 .) 